\title{
In Vitro Evaluation of Portuguese Propolis and Floral Sources for Antiprotozoal, Antibacterial and Antifungal Activity
}

\author{
Soraia I. Falcão, ${ }^{1,2}$ Nuno Vale, ${ }^{3}$ Paul Cos, ${ }^{4}$ Paula Gomes, ${ }^{3}$ Cristina Freire, ${ }^{2}$ Louis Maes ${ }^{4}$ \\ and Miguel Vilas-Boas ${ }^{1 *}$ \\ ${ }^{1}$ CIMO - Escola Superior Agrária, Instituto Politécnico de Bragança, Campus de Sta. Apolónia, Apartado 1172, 5301-855 Bragança, Portugal \\ ${ }^{2}$ REQUIMTE - Departamento de Química e Bioquímica, Faculdade de Ciências da Universidade do Porto, Rua do Campo Alegre, \\ 687, 4169-007 Porto, Portugal \\ ${ }^{3}$ CIQ-UP, Departamento de Química e Bioquímica, Faculdade de Ciências da Universidade do Porto, Rua do Campo Alegre, 687, \\ 4169-007 Porto, Portugal \\ ${ }^{4}$ Laboratory of Microbiology, Parasitology and Hygiene (LMPH), University of Antwerp, Universiteitsplein 1, B-2610 Antwerp, Belgium
}

\begin{abstract}
Propolis is a beehive product with a very complex chemical composition, used since ancient times in several therapeutic treatments. As a contribution to the improvement of drugs against several tropical diseases caused by protozoa, we screened Portuguese propolis and its potential floral sources Populus $x$ Canadensis and Cistus ladanifer against Plasmodium falciparum, Leishmania infantum, Trypanosoma brucei and Trypanosoma cruzi. The toxicity against MRC-5 fibroblast cells was evaluated to assess selectivity. The in vitro assays were performed following the recommendations of WHO Special Programme for Research and Training in Tropical Diseases (TDR) and revealed moderate activity, with the propolis extracts presenting the relatively highest inhibitory effect against T. brucei. Additionally, the antimicrobial activity against Staphylococcus aureus, Candida albicans, Trichophyton rubrum and Aspergillus fumigatus was also verified with the better results observed against T. rubrum. The quality of the extracts was controlled by evaluating the phenolic content and antioxidant activity. The observed biological activity variations are associated with the variable chemical composition of the propolis and the potential floral sources under study. Copyright @ 2013 John Wiley \& Sons, Ltd.
\end{abstract}

Keywords: propolis; antiprotozoal activity; antimicrobial activity; phenolic compounds; antioxidant activity.

\section{INTRODUCTION}

Propolis is a resinous bee product collected by honeybees (Apis melifera L.) from parts of plants, buds and exudates on the vegetation around the hive and enriched with wax, salivary and enzymatic secretions (Marcucci, 1995). This natural resinous substance plays an important role as construction and defence material against infections in the hive (Bankova et al., 2000) and preserves some of the medicinal properties of certain plants. For instance, Cistus species secrete large amounts of a strong aromatic resin on the surface of leaves and stems, rich in polyphenols and used since ancient times to treat diarrhea, dysentery and menstruation problems (Robles et al., 2003). The Populus bud exudates have long been used in popular medicine for treating wounds and ulcers. Their antiseptic, anti-inflammatory and antimicrobial properties have been documented (Scaysbrook et al., 1992; Zhang et al., 2006).

During the last decades, propolis has become the subject of increased scientific interest for its wide variety of pharmacological and biological properties, such as antibacterial (Sforcin et al., 2000), antifungal (MilletClerc et al., 1987), antiviral (Amoros et al., 1992),

\footnotetext{
* Correspondence to: Miguel Vilas-Boas, CIMO - Escola Superior Agrária Instituto Politécnico de Bragança, Campus de Sta. Apolónia, Apartado 1172, 5301-855 Bragança, Portugal.

E-mail: mvboas@ipb.pt
}

antiprotozoal (Monzote et al., 2012), antioxidant, hepatoprotective, antitumor and anti-inflammatory (Banskota et al., 2001) activities. Approximately half of the propolis content corresponds to phenolic compounds, while beeswax, volatiles and pollen account for, respectively, $30 \%, 10 \%$ and $5 \%$ (Burdock, 1998). The chemical composition of propolis is highly variable and complex, depending strongly on the plant sources available at the site of collection and thus on the geographic and climatic characteristics of the apiary location. In regions of temperate climate, bees obtain resins from the buds of Populus spp., and derived propolis is mainly composed by flavonoids, phenolic acids and their esters. In tropical areas, species of Baccharis spp. in Brazil and Clusia spp. in Cuba and Venezuela are the main sources of propolis, with prenylated $p$-coumaric acids and polyisoprenylated benzophenones as the main compounds in Baccharis and Clusia-derived propolis, respectively (Bankova et al., 2000). Despite the compositional differences between propolis types, their biological properties are very similar, e.g. all possess antimicrobial activity.

Propolis from North-eastern Portugal was recently characterized, providing identification of 37 phenolic compounds, with pinocembrin, chrysin and pinobanksin3-O-acetate being the most abundant (Falcão et al., 2010). The phenolic compounds show strong antioxidant activity and decrease erythrocyte membrane fragility in hereditary spherocytosis (Moreira et al., 2011). Propolis extracts also strongly suppress the proliferation of 
primary renal cancer cells in a concentration-dependent manner (Valente et al., 2011) and are able to exert moderate neuroprotection through the inhibition of caspase-3 activation (Cardoso et al., 2011). Portuguese propolis extracts were shown to have antimicrobial activity against Staphylococcus aureus, Pseudomonas aeruginosa, Escherichia coli and Candida albicans (Silva et al., 2012), with the Gram-negative bacteria being more sensitive to the bee glue. To the best of our knowledge, there are yet no studies on the activity of Portuguese propolis against pathogenic protozoa.

In this study, Portuguese propolis phenolic extracts and their potential plant sources were screened in vitro for their activity against the pathogenic protozoa Plasmodium falciparum, Leishmania infantum, Trypanosoma cruzi and Trypanosoma brucei. To assess selectivity of action, cytotoxicity against MRC-5 fibroblasts and antibacterial and antifungal activities were evaluated in parallel. The quality of the extracts was assessed by evaluating their phenolic content and antioxidant activity.

\section{MATERIALS AND METHODS}

Chemicals and reagents. Standard compounds such as galangin, pinocembrin, caffeic acid, chloroquine, melarsoprol, benznidazole, miltefosine, tamoxifen, as well as other chemicals, such as aluminium chloride, potassium ferricyanide, ferric chloride, trichloroacetic acid, 2,2diphenyl-1-picrylhydrazyl (DPPH) and dimethyl sulfoxide (DMSO) were all purchased from Sigma Chemical Co (St. Louis, MO, USA). Analytical grade reagents like sodium carbonate, potassium hydroxide, Folin-Ciocalteau reagent, acetic acid, sulphuric acid, formic acid, ethanol and methanol were obtained from Panreac (Barcelona, Spain). 2,4-Dinitrophenylhydrazine (DNP), ampicillin and miconazole were from Fluka Chemical Co (St. Louis, MO, USA). Water was treated in a Milli-Q water purification system (TGI Pure Water Systems, USA).

Samples origin and preparation. The study was performed on propolis and plant samples present in the hive neighborhood that were reported (Bankova et al., 2000) as propolis floral sources. Two different propolis samples were collected from beekeepers after the honey harvesting season by scratching the hive walls and frames, followed by the removal of debris of wood and bees. Sample A1 was collected in North-eastern Portugal (Bragança county), while sample A2 was collected from the centre of Portugal (Leiria county). For the floral sources of the bee glue, the buds exudates and surface material present on the leaves and stems of Populus $x$ Canadensis Moenchen (an hybrid species of Populus) male (PM) and female specimens (PF) and Cistus ladanifer L. (C) were collected during spring. All samples were stored at $-20^{\circ} \mathrm{C}$ until analysis. The voucher specimens are deposited at the herbarium of Escola Superior Agrária of Instituto Politécnico de Bragança with the reference number BRESA 5174, BRESA 5355 and BRESA 5356 for C, PF and PM, respectively.

The extraction was made according to the work previously described (Falcão et al., 2010). Prior to the extraction, $1 \mathrm{~g}$ of powdered propolis sample was homogenized and mixed with $10 \mathrm{~mL}$ of $80 \%$ of ethanol/water and kept at $70{ }^{\circ} \mathrm{C}$ for $1 \mathrm{~h}$. The resulting mixtures were filtered, and the residues were re-extracted in the same conditions. After the second extraction, the filtrates were combined, concentrated and freeze-dried. For biological studies, stock solutions of the extracts were prepared in $13 \%$ DMSO/water (propolis) or $100 \%$ DMSO (floral sources) at $20 \mathrm{mg} / \mathrm{mL}$.

Total phenolic content. The total phenolic content was determined with a modified Folin-Ciocalteu method (Singleton and Rossi, 1965). An ethanolic extract aliquot $(0.5 \mathrm{~mL})$ was mixed with $0.25 \mathrm{~mL}$ Folin-Ciocalteu's reagent. After $3 \mathrm{~min}, 1 \mathrm{~mL}$ of a saturated sodium carbonate solution was added to the mixture, and the volume adjusted to $5 \mathrm{~mL}$ with distilled water. The solution was then heated at $70^{\circ} \mathrm{C}$ for $10 \mathrm{~min}$, cooled in the dark for $30 \mathrm{~min}$, and the optical density was measured at $760 \mathrm{~nm}$ (Analytikijena 200-2004 spectrophotometer, Analytik Jena, Jena, Germany). The ethanolic extracts were evaluated at the final concentration of $0.05 \mathrm{mg} / \mathrm{L}$, and the total phenolic content was expressed in milligrams per gram of caffeic acid:galangin:pinocembrin (1:1:1) equivalents. For each extract, measurements were performed in three independent experiments.

Flavone and flavonol content. The content of flavone and flavonol was determined based on the method previously described (Cvek et al., 2007) with minor modifications. Briefly, $2 \mathrm{~mL}$ of the ethanolic extract was added to $0.2 \mathrm{~mL}$ of aluminium chloride solution ( $2 \%$ aluminium chloride in $5 \%$ acetic acid/methanol), and the volume was adjusted to $5 \mathrm{~mL}$ with $5 \%$ acetic acid/methanol. After $30 \mathrm{~min}$ at room temperature, the optical density was measured at $415 \mathrm{~nm}$. The ethanolic extracts were evaluated in triplicate at a final concentration of $0.1 \mathrm{mg} / \mathrm{L}$, and the flavone and flavonol contents were expressed as milligrams per gram of galangin equivalents.

Flavanone and dihydroflavonol content. Flavanones and dihydroflavonols were determined using a previously described method (Popova et al., 2004). Briefly, $1 \mathrm{~mL}$ of the test solution and $2 \mathrm{~mL}$ of DNP solution $(1 \mathrm{~g}$ of DNP was dissolved in $2 \mathrm{~mL}$ of $96 \%$ sulphuric acid and the volume was adjusted to $100 \mathrm{~mL}$ with methanol) were heated at $50^{\circ} \mathrm{C}$ for $50 \mathrm{~min}$. After cooling to room temperature, the mixture was diluted to $10 \mathrm{~mL}$ with $10 \%$ potassium hydroxide in methanol (w/v). An aliquot $(1 \mathrm{~mL})$ of the resulting solution was added to $10 \mathrm{~mL}$ of methanol and diluted to $50 \mathrm{~mL}$ with methanol. Finally, the optical density was measured at $486 \mathrm{~nm}$. The content in flavanones and dihydroflavonols was evaluated in triplicate and expressed as milligrams per gram of pinocembrin equivalents.

DPPH free radical-scavenging activity. The antioxidant effect on DPPH radical was measured according to the procedure described previously (Brand-Williams et al., 1995) with some modifications. The reaction was performed in a 96-well microplate where an aliquot of propolis extract $(0.08 \mathrm{~mL})$ in $80 \%$ ethanol containing 
different extract concentrations $(2.5-40 \mu \mathrm{g} / \mathrm{mL})$ was added to $0.220 \mathrm{~mL}$ of DPPH $(0.025 \mathrm{~g} / \mathrm{L}$ in $80 \%$ ethanol, daily prepared). After $45 \mathrm{~min}$ at room temperature, optical density was measured at $515 \mathrm{~nm}$ using an ELX800 Microplate Reader (Bio-Tek Instruments, Inc.). A mixture of phenolic compounds (caffeic acid: galangin: pinocembrin; 1:1:1) was used as standard. The percentage of radical inhibition was calculated from the absorbance of the DPPH solution without sample $\left(\mathrm{A}_{\mathrm{DPPH}}\right)$ and of the DPPH solution with sample $\left(\mathrm{A}_{\text {sample }}\right)$, using the following equation: $\%$ Inhibition $=\left[\left(\mathrm{A}_{\mathrm{DPPH}}-\mathrm{A}_{\text {sample }}\right) / \mathrm{A}_{\mathrm{DPPH}}\right] \times 100$.

This percentage was plotted against the extract concentration to obtain the amount of antioxidant needed to decrease the initial DPPH concentration by $50 \%$ $\left(\mathrm{EC}_{50}\right)$. The assay was performed in triplicate.

Reducing power. The reducing power of the propolis extracts was determined according to the method of Oyaizu (1986). $2.5 \mathrm{~mL}$ of the propolis ethanolic extract $(10-200 \mu \mathrm{g} / \mathrm{mL})$ was mixed with $2.5 \mathrm{~mL}$ phosphate buffer $(0.2 \mathrm{~mol} / \mathrm{L}, \mathrm{pH} 6.6)$ and $2.5 \mathrm{~mL}$ of $1 \%$ potassium ferricyanide. The mixture was incubated at $50{ }^{\circ} \mathrm{C}$ for $20 \mathrm{~min}$. Then, $2.5 \mathrm{~mL}$ of $10 \%$ trichloroacetic acid was added to the mixture followed by centrifugation at $3000 \mathrm{rpm}$ (Centurion $\mathrm{K}_{2} \mathrm{R}$ series) for $10 \mathrm{~min}$. The upper layer of the solution $(2.5 \mathrm{~mL})$ was mixed with distilled water $(2.5 \mathrm{~mL})$ and $\mathrm{FeCl}_{3}(0.5 \mathrm{~mL}, 0.1 \%)$. Finally, the optical density was measured at $700 \mathrm{~nm}$. A mixture of caffeic acid: galangin: pinocembrin (1:1:1) was used as standard. An increase of the optical density for the reaction mixture indicates a higher reducing power. The complex with absorbance is the result of the phenolic compound reaction during the reduction of iron. The assay was run in triplicate in independent experiments.

Test plate production for antimicrobial evaluation. The experiments were performed in 96-well plates (Greiner) at four-fold dilutions in a dose-titration range of $64 \mu \mathrm{g} / \mathrm{mL}$ to $0.25 \mu \mathrm{g} / \mathrm{mL}$. Dilutions were carried out by a programmable precision robotic station (BIOMEK 2000, Beckman, USA). Each plate also contained mediumcontrols (blanks: 0\% growth), infected untreated controls (negative control: 100\% growth) and reference controls (positive control). Tests were run in duplicate in two independent experiments.

Biological screening tests. The integrated panel of microbial screens for the present study and the standard screening methodologies were adopted as described before (Cos et al., 2006). Extracts with high cytotoxicity and/or non-selective activity against the different protozoa were not titrated down to their exact IC50.

Antiplasmodial activity. The chloroquine-susceptible $P$. falciparum GHA-strain was used. Parasites were cultured in human erythrocytes $\mathrm{A}^{+}$at $37^{\circ} \mathrm{C}$ under a low oxygen atmosphere $\left(3 \% \mathrm{O}_{2}, 4 \% \mathrm{CO}_{2}\right.$ and $\left.93 \% \mathrm{~N}_{2}\right)$ in a modular incubation chamber (Trager and Jensen, 1976). The culture medium was RPMI-1640 supplemented with $10 \%$ human serum. Two hundred microliters of infected human red blood cells suspension (1\% parasitemia, 2\% hematocrit) were added to each well of the plates with test compounds and incubated for $72 \mathrm{~h}$. After incubation, test plates were frozen at $-20^{\circ} \mathrm{C}$. Parasite multiplication was measured by the Malstat method (Makler et al., 1993). One hundred microliters of Malstat reagent was transferred in a new plate and mixed with $20 \mu \mathrm{L}$ of the hemolysed parasite suspension for $15 \mathrm{~min}$ at room temperature. After addition of $20 \mu \mathrm{L}$ nitroblue tetrazolium (NBT)/phenazine ethosulphate (PES) solution (1.6 mg of NBT and $0.1 \mathrm{mg}$ of PES) and $2 \mathrm{~h}$ incubation in the dark, the optical density was spectrophotometrically read at $655 \mathrm{~nm}$ (Biorad 3550-UV microplate reader). Percentage of growth inhibition was compared to the negative blanks. Chloroquine was used as reference drug.

Antitrypanosomal activity. Trypomastigotes of T. brucei Squib-427 strain (suramin-sensitive) were cultured at $37^{\circ} \mathrm{C}$ and $5 \% \mathrm{CO}_{2}$ in Hirumi-9 medium (Hirumi and Hirumi, 1989), supplemented with $10 \%$ fetal calf serum (FCS). Assays were performed by adding $1.5 \times 10^{4}$ trypomastigotes/well. After $72 \mathrm{~h}$ incubation, parasite growth was assessed fluorimetrically by adding resazurin (Raz et al., 1997) for $24 \mathrm{~h}$ at $37^{\circ} \mathrm{C}$. Fluorescence was measured using a GENios Tecan fluorimeter (excitation $530 \mathrm{~nm}$, emission $590 \mathrm{~nm}$ ). Melarsoprol was used as reference drug.

Amastigotes of T. cruzi (Tulahuen CL2 strain, nifurtimox-sensitive) were maintained on MRC-5 cells in minimal essential medium (MEM) supplemented with $20 \mathrm{mML}$-glutamine, $16.5 \mathrm{mM}$ sodium hydrogen carbonate and $5 \% \mathrm{FCS}$ at $37^{\circ} \mathrm{C}$ and $5 \% \mathrm{CO}_{2}$. To determine in vitro activity, $4 \times 10^{3}$ MRC-5 cells and $4 \times 10^{4}$ parasites were added to each well of the test plate with compound. After incubation at $37^{\circ} \mathrm{C}$ for 7 days, parasite growth was assessed by adding $\beta$-galactosidase substrate chlorophenol red $\beta$-D-galactopyranoside (Buckner et al., 1996) for $4 \mathrm{~h}$ at $37^{\circ} \mathrm{C}$. The colour reaction was read at $540 \mathrm{~nm}$, and optical density values were expressed as a percentage of the blank controls. Benznidazole was used as reference drug.

Antileishmanial activity. Amastigotes of L. infantum (MHOM/ET 67), used to infect primary peritoneal mouse macrophages, were collected from the spleen of donor hamsters with an established Leishmania infection of 6 to 8 weeks. After aseptic removal of the spleen, a number of smear impressions were made on a microscope slide and stained with Giemsa stain to enumerate the amastigote spleen burden using the Stauber index (total number of amastigotes $=$ weight of spleen $(\mathrm{g}) \times$ number amastigotes/cell $\left.\times 2 \times 10^{8}\right)$. To purify the amastigotes, the spleen was grinded in $10 \mathrm{~mL}$ culture medium in a tissue grinder; the splenic cell suspension was transferred in a sterile $15 \mathrm{~mL}$ centrifugation tube and centrifuged for $10 \mathrm{~min}$ at $300 \mathrm{rpm}$ and $4{ }^{\circ} \mathrm{C}$ to remove most of the cell debris. The supernatant was then transferred to a sterile $15 \mathrm{~mL}$ centrifugation tube and centrifuged for $10 \mathrm{~min}$ at $2200 \mathrm{rpm}$ and $4^{\circ} \mathrm{C}$; the supernatant was discarded, and the pellet was re-suspended in $10 \mathrm{~mL}$ complete culture medium. After one additional washing cycle and appropriate dilution, this suspension was used as infection inoculum for the in vitro macrophage cultures. 
To determine in vitro antileishmanial activity, $3 \times 10^{4}$ macrophages were seeded in each well of a 96-well plate. After $48 \mathrm{~h}$ outgrowth, $5 \times 10^{4}$ amastigotes/well were added and incubated for $2 \mathrm{~h}$ at $37^{\circ} \mathrm{C}$. Pre-diluted compounds were subsequently added, and the plates were further incubated for $120 \mathrm{~h}$ at $37^{\circ} \mathrm{C}$ and $5 \% \mathrm{CO}_{2}$. Parasite burdens were determined microscopically after Giemsa staining and expressed as a percentage of the blank controls without propolis sample. Miltefosine was used as reference drug.

Cytotoxicity assay. MRC- $5_{\mathrm{Sv} 2}$ human foetal lung fibroblasts were cultivated in MEM, supplemented with Lglutamine $(20 \mathrm{mM}), 16.5 \mathrm{mM}$ sodium hydrogen carbonate and $5 \% \mathrm{FCS}$ at $37^{\circ} \mathrm{C}$ and $5 \% \mathrm{CO}_{2}$. For the assay, $10^{4}$ MRC-5 cells/well were seeded onto the test plates containing the pre-diluted compounds and incubated at $37^{\circ} \mathrm{C}$ and $5 \% \mathrm{CO}_{2}$ for $72 \mathrm{~h}$. Cell viability was determined after addition of resazurin. Tamoxifen was used as reference drug.

Antibacterial and antifungal assays. These assays have been also performed at the Laboratory of Microbiology, Parasitology and Hygiene (LMPH), Antwerp University, Belgium (Cos et al., 2006) against Staphylococcus aureus, Candida albicans, Trichophyton rubrum and Aspergillus fumigatus. $\mathrm{IC}_{50}$ values were determined from five 4-fold dilutions, starting from a maximum concentration of $64 \mu \mathrm{g} / \mathrm{mL}$. Ampicillin was used as reference for S. aureus, while miconazole was used as reference for Candida, Trichophyton and Aspergillus. The impact of toxicity was determined by analyzing the selectivity index (SI), the ratios between the MRC- $5_{\mathrm{SV} 2}$ cytotoxic and the antimicrobial IC50 values.

Statistical analysis. For the phenolic composition and antioxidant activity, the assays were carried out in triplicate and presented in the figures as mean values with standard deviation. The results were analyzed using one-way analysis of variance followed by Tukey's HSD test with $\mathrm{a}=0.05$. The analysis was performed using SPSS v. 18.0 program. The result of this analysis can be found in the figures: samples with the same letter are statistically no different.

For the antiprotozoal, antibacterial and antifungal activity, in each experiment, the $50 \%$ of microbial growth $\left(\mathrm{IC}_{50}\right)$ and human cell growth $\left(\mathrm{CC}_{50}\right)$ inhibition value was determined from the concentration-response curves, and the results were expressed as the mean \pm standard deviation of two independent experiments.

\section{RESULTS AND DISCUSSION}

Propolis is a bee product with a complex chemical composition which is largely dependent on its plant origin. Populus bud exudates and Cistus ladanifer L. leaf exudates are documented to be potential resin sources for propolis in Europe (Bankova et al., 2000). In the present study, these plants were abundant in the hive neighborhood, and their phenolic content, antioxidant and antimicrobial activities were evaluated and compared to propolis.

Figure 1 shows the content of total phenolic compounds, flavones/flavonols and flavanones/dihydroflavonols in propolis and in the Cistus and Populus ethanolic extracts. All values are statistically different. The highest total phenolic content was found in the propolis samples, but there is no great difference between the two samples of distinct geographical origin. The total phenolic content of $329 \mathrm{mg} / \mathrm{g}$ for the central propolis (A2) is in line with other studies on Portuguese propolis (Moreira et al., 2008). For the plant extracts, the values ranged from 167 to $278 \mathrm{mg} / \mathrm{g}$ with the male Populus sample revealing a higher value than Cistus ladanifer.

For the flavones and flavonols quantified by the aluminium chloride method, a higher content was also found in propolis compared to the plant extracts. North-eastern and central propolis samples showed values ranging from 81 to $97 \mathrm{mg} / \mathrm{g}$, while the plant extracts contained 39 to $47 \mathrm{mg} / \mathrm{g}$ (Fig. 1). The flavanones and dihydroflavonols quantified by the DNP method were present in smaller quantities in the Cistus extract (113 mg/g) compared with propolis and Populus ethanolic extracts (Fig. 1).

Phenolic compounds, due to their hydroxyl groups, are known to act as antioxidants (Rice-Evans et al., 1996). Therefore, the activity of the extracts was evaluated with the DPPH free radical scavenging method (Brand-Williams et al., 1995). The $\mathrm{EC}_{50}$ values are shown in Fig. 2A with all propolis and plant extracts possessing significant free radical scavenging activity. The extracts of male and female Populus $x$ canadensis bud exudates exhibited the highest activity with $\mathrm{EC}_{50}$ values of 0.014 and $0.015 \mathrm{mg} / \mathrm{mL}$, respectively. These values were close to the standard mixture of pure compounds used in this study (caffeic acid: galangin: pinocembrin, 1:1:1), pointing out the significant activity of these natural extracts. The propolis samples showed an $\mathrm{EC}_{50}$ value around $0.018 \mathrm{mg} / \mathrm{mL}$, while Cistus ladanifer resin presented the lowest scavenging activity (Fig. 2A).

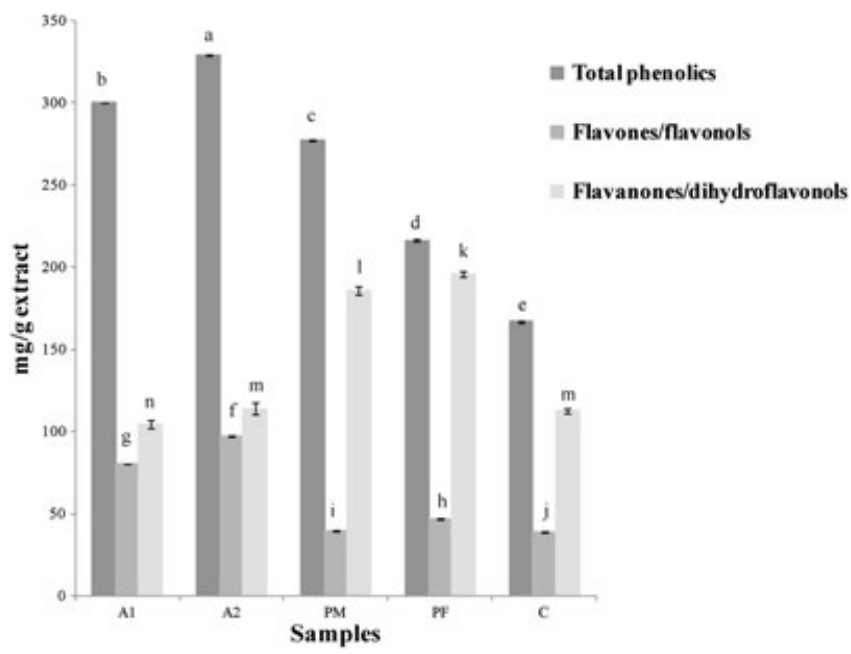

Figure 1. Phenolic composition of propolis and their ethanolic extracts. A1, North-eastern propolis; A2, Central propolis; PM, Populus $x$ canadensis male; PF, Populus $x$ canadensis female; C, Cistus ladanifer. Total phenolics were expressed as caffeic acid: galangin: pinocembrin $(1: 1: 1)$ equivalents. Flavones/flavonols were expressed as galangin equivalents. Flavanones/dihydroflavonols were expressed as pinocembrin equivalents. In each column, different letters $(a-n)$ mean significant differences between samples $(p<0.05)$ 

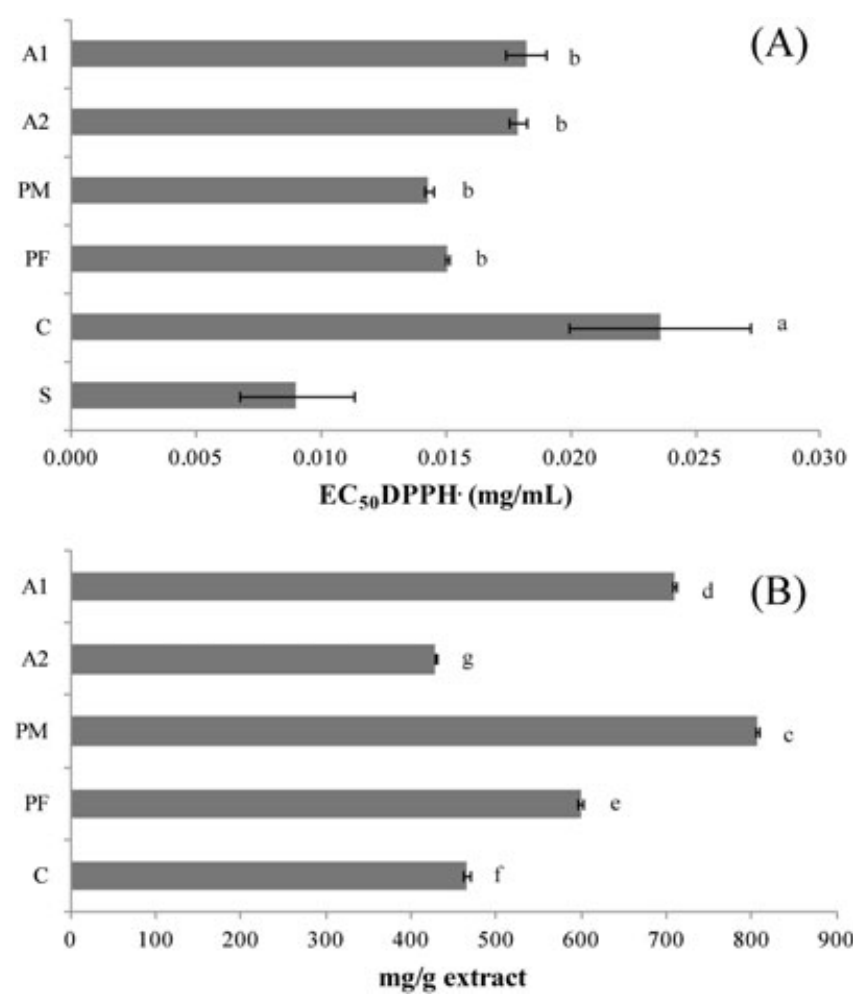

Figure 2. Antioxidant activity of propolis and ethanolic plant extracts (A) against DPPH and (B) reducing power. A1, Northeastern propolis; A2, Central propolis; PM, Populus $x$ canadensis male; PF, Populus $x$ canadensis female; C, Cistus ladanifer; S, caffeic acid: galangin: pinocembrin $(1: 1: 1)$ used as standard. Reducing power was expressed as caffeic acid: galangin: pinocembrin $(1: 1: 1)$ equivalents. In each column, different letters $(a-g)$ mean significant differences between samples $(p<0.05)$

$\mathrm{Fe}(\mathrm{III})$ reduction was used as an indicator of electrondonating activity, which is an important mechanism for phenolic antioxidant action (Yildirim et al., 2001). The reducing power was expressed as caffeic acid: galangin: pinocembrin (1:1:1) equivalents (Fig. 2B). Once again, the best activity was found for the male Populus $x$ canadensis followed by the propolis sample A1 with values of $807 \mathrm{mg} / \mathrm{g}$ and $710 \mathrm{mg} / \mathrm{g}$ respectively. Sample A 2 revealed a very low reduction power, even lower than the plant extracts.

Considering the above, the highest radical scavenging ability or reduction power was not found for the samples with the richer phenolic content, meaning that the observed bioactivity cannot be judged solely on the basis of the overall phenolic content. In fact, some of the individual phenolic compounds present in the extract can play a more important role in the activity than others.

Portuguese propolis phenolic extracts and their potential plant sources were evaluated for in vitro activity against the pathogenic protozoa $P$. falciparum, L. infantum, $T$. cruzi and T. brucei (Table 1). To assess selectivity of action, cytotoxicity against MRC-5 fibroblasts was included.

Activity against $P$. falciparum was found for the propolis sample from the central region of Portugal with an $\mathrm{IC}_{50}$ of $8.83 \mu \mathrm{g} / \mathrm{mL}$, while the phenolic extract of male Populus showed the highest SI $(\mathrm{SI}=4)$. Filho et al. (2009) reported an $\mathrm{IC}_{50}$ of $20 \mu \mathrm{g} / \mathrm{mL}$ (SI > 2.4) for Brazilian green propolis and of $25 \mu \mathrm{g} / \mathrm{mL}(\mathrm{SI}>1.9)$ for the extract of Baccharis dracunculifolia, the floral origin of green propolis. These values are actually in the same range as our results and in fact reveal that our samples A2 and PM show a marginally higher antiplasmodial potential, which may be associated with the richer composition in flavonoids for propolis from Populus (Machado et al., 2007). For an antimalarial 'hit', the WHO Special Programme for Research and Training in Tropical Diseases defines an activity criterion to be $\mathrm{IC}_{50}<0.2 \mu \mathrm{g} / \mathrm{mL}$ with SI $>20$ (TDR, 2007). Therefore, the relevance of the antimalarial action of our samples requires further research. Propolis toxicity was referred by Marcucci (1995) and Burdock (1998) to be associated with some of the propolis components, namely caffeic acid esters present in the European propolis with origin in the poplar buds. The synergistic effect of all compounds in the entire extract can be responsible for a real loss of activity, while the isolated compounds or fractions of it can indeed reveal a higher activity (Filho et al., 2009).

For L. infantum, propolis samples and male and female Populus showed a similar $\mathrm{IC}_{50}$ value of $8.11 \mu \mathrm{g} / \mathrm{mL}$. Cistus ladanifer showed the lowest activity with an $\mathrm{IC}_{50}$ value of $32.46 \mu \mathrm{g} / \mathrm{mL}$. Duran et al. (2011) reported antileishmanial activity on two different Turkish propolis samples with $\mathrm{IC}_{50}$ values ranging between 125 and $325 \mu \mathrm{g} / \mathrm{mL}$. Filho et al. (2009) presented $\mathrm{IC}_{50}$ values of 49 and $45 \mu \mathrm{g} / \mathrm{mL}$ for a green propolis sample and its plant source $B$. dracunculifolia against $L$. donovani.

Our results for the activity against $T$. cruzi were very similar between all the samples tested, ranging from 6.16 to $8.59 \mu \mathrm{g} / \mathrm{mL}$ (Table 1). Prytzyk et al. (2003) and Cunha et al. (2004) tested the activity against $T$. cruzi in Bulgarian and Brazilian propolis whereby all the extracts showed a lower activity than the Portuguese propolis, with values

Table 1. Antiprotozoal activity against $P$. falciparum, L. infantum, T. cruzi, T. brucei and cytotoxicity in MRC-5 fibroblast cells

\begin{tabular}{|c|c|c|c|c|c|}
\hline \multirow[b]{2}{*}{ Sample $^{a}$} & \multicolumn{5}{|c|}{$\mathrm{IC}_{50} \mu \mathrm{g} / \mathrm{mL}$ (mean $\pm \mathrm{sd}$ ) -- duplicate testing } \\
\hline & P. falciparum & L. infantum & T. cruzi & T. brucei & MRC-5 \\
\hline A1 & $30.1 \pm 4.1$ & $8.1 \pm 1.0$ & $6.2 \pm 1.9$ & $1.7 \pm 0.5$ & $12.0 \pm 4.3$ \\
\hline A2 & $8.8 \pm 1.8$ & $8.1 \pm 0.9$ & $7.7 \pm 2.1$ & $3.8 \pm 1.2$ & $9.7 \pm 3.5$ \\
\hline PM & $10.9 \pm 2.1$ & $8.1 \pm 1.1$ & $7.8 \pm 1.8$ & $5.7 \pm 1.3$ & $38.4 \pm 5.8$ \\
\hline PF & $28.5 \pm 3.8$ & $8.1 \pm 1.3$ & $7.6 \pm 1.6$ & $5.3 \pm 1.9$ & $33.7 \pm 6.2$ \\
\hline C & $17.0 \pm 2.5$ & $32.5 \pm 2.7$ & $8.6 \pm 2.0$ & $2.0 \pm 0.4$ & $32.2 \pm 4.5$ \\
\hline Chloroquine & $0.04 \pm 0.01$ & - & - & - & - \\
\hline Miltefosine & - & $2.4 \pm 0.8$ & - & - & - \\
\hline Benznidazole & - & - & $2.5 \pm 0.6$ & - & - \\
\hline Melarsoprol & - & - & - & $0.005 \pm 0.001$ & - \\
\hline
\end{tabular}

Tamoxifen

$10.5 \pm 2.5$

aSamples: A1: North-eastern propolis; A2: Central propolis; PM: Populus x canadensis male; PF: Populus x canadensis female; C: Cistus ladanifer. 
ranging between 108.8 and $1065 \mu \mathrm{g} / \mathrm{mL}$ for Bulgarian propolis and between 421 and $1437 \mu \mathrm{g} / \mathrm{mL}$ for Brazilian propolis. These biological activity variations are likely associated with different chemical compositions presented by the different propolis types. No cytotoxicity tests were performed in that study.

For all antiprotozoal assays, the relatively highest activities were found against $T$. brucei. Sample A1 was the most active with an $\mathrm{IC}_{50}$ value of $1.70 \mu \mathrm{g} / \mathrm{mL}$ (Table 1) which is in the same range as the antitrypanosomal reference drug suramin (Otoguro et al., 2012). Isolation of phenolic compounds from propolis can significantly increase the activity: $\beta$-phenylethyl caffeate showed a high activity $\left(\mathrm{IC}_{50}=0.013 \mu \mathrm{g} / \mathrm{mL} ; \mathrm{SI}=150\right)$, while 2,2-dimethylallyl caffeate exhibited a reduced antitrypanosomal activity $\left(\mathrm{IC}_{50}=12.5 \mu \mathrm{g} / \mathrm{mL}\right)$, demonstrating the potential loss of activity when testing the entire extract (Otoguro et al. (2012).

The activity of the propolis and plant ethanolic extracts was also evaluated against bacteria and fungi (Table 2). The results reveal that the plant extracts do no exhibit relevant antimicrobial activity compared to propolis ethanolic extracts, with exception of T. rubrum. In general, both propolis samples revealed a similar antimicrobial effect, with the highest activity found against T. rubrum and the lowest against $A$. fumigatus. Recently, Silva et al. (2012) verified that propolis from the North and Centre of Portugal was more active against $S$. aureus than against $C$. albicans, which agrees with our results. In fact, considering that the $\mathrm{IC}_{50}$ value for $T$. rubrum is even lower than for $S$. aureus, it can be considered a promising result. However, one should also consider the cytotoxicity, which was rather high in our study.

In summary, the present study focused on the screening of Portuguese propolis samples and two potential plant sources against pathogenic protozoa, revealing reduced activity and low selectivity. Since propolis has a complex chemical composition, an extract fractionation will be
Table 2. Antimicrobial activity against Staphylococcus aureus, Candida albicans, Trichophyton rubrum and Aspergillus fumigatus

\begin{tabular}{lcccc}
\hline & \multicolumn{4}{c}{$\mathrm{IC}_{50} \mu \mathrm{g} / \mathrm{mL}(\mathrm{mean} \pm \mathrm{sd})$-- duplicate testing } \\
\cline { 2 - 5 } Sample $^{\mathrm{a}}$ & S. aureus & C. albicans & T. rubrum & A. fumigatus \\
\hline A1 & $24.6 \pm 3.8$ & $32.0 \pm 3.2$ & $14.5 \pm 1.2$ & $>64.0$ \\
A2 & $25.7 \pm 2.9$ & $43.1 \pm 4.1$ & $11.0 \pm 0.9$ & $>64.0$ \\
PM & $>64.0$ & $33.6 \pm 3.5$ & $38.9 \pm 2.3$ & $>64.0$ \\
PF & $>64.0$ & $>64.0$ & $24.2 \pm 2.1$ & $>64.0$ \\
C & $>64.0$ & $>64.0$ & $20.8 \pm 1.8$ & $>64.0$ \\
Ampicillin & $1.1 \pm 0.3$ & & & \\
Miconazole & & $4.0 \pm 1.4$ & $0.5 \pm 0.1$ & $1.5 \pm 0.8$ \\
\hline
\end{tabular}

aSamples: A1: North-eastern propolis; A2: Central propolis; PM: Populus $x$ canadensis male; PF: Populus $x$ canadensis female; C: Cistus ladanifer

needed to identify putative active components. Also, these results were evaluated according to criteria set up by the WHO Special Programme for Research and Training in Tropical Diseases, what should be considered by future studies with others propolis samples to enable effective comparisons between scientific findings.

\section{Acknowledgements}

Soraia I. Falcão thanks FCT for the PhD grant SFRH/BD/44855/2008. N. Vale thanks FCT for the Post-Doc grant SFRH/BPD/48345/2008. Thanks also to FCT for financial support provided to CIMO (PEst-OE/ AGR/UI0690/2011) and CIQ-UP (PEst-C/QUI/UI0081/2011). Thanks are due to the National Federation of Portuguese Beekeepers, for supplying propolis samples.

\section{Conflict of Interest}

The authors report no conflict of interest.

\section{REFERENCES}

Amoros M, Sauvager F, Girre L, Cormier M. 1992. In vitro antiviral activity of propolis. Apidologie 23: 231-240.

Bankova V, Castro SL, Marcucci MC. 2000. Propolis: recent advances in chemistry and plant origin. Apidologie 31: 3-15.

Banskota AH, Tezuka Y, Kadota SH. 2001. Recent progress in pharmacological research of propolis. Phytother Res 15: 561-571.

Brand-Williams W, Cuvelier ME, Berset C. 1995. Use of free radical method to evaluate antioxidant activity. $\angle W T$ 28: 25-30.

Buckner FS, Verlinde CL, La Flamme AC, Van Voorhis WC. 1996. Efficient technique for screening drugs for activity against Trypanosoma cruzi using parasites expressing betagalactosidase. Antimicrob Agents Chemother 40: 2592-2597.

Burdock GA. 1998. Review of the biological properties and toxicity of bee propolis (propolis). Food Chem Toxicol 36: 347-363.

Cardoso SM, Ribeiro M, Ferreira IL, Rego AC. 2011. Northeast Portuguese propolis protects against staurosporine and hydrogen peroxide-induced neurotoxicity in primary cortical neurons. Food Chem Toxicol 49: 2862-2868.

Cos P, Vlietinck AJ, Berghe DV, Maes L. 2006. Anti-infective potential of natural products: How to develop a stronger in vitro 'proof-of-concept'. J Ethnopharmacol 106: 290-302.

Cunha IBS, Salomão K, Shimizu M, et al. 2004. Antitrypanosomal activity of Brazilian propolis from Apis mellifera. Chem Pharm Bull 52: 602-604.

Cvek J, Medić-Šarić M, Jasprica I, et al. 2007. Optimization of an extraction procedure and chemical characterization of Croatian propolis tinctures. Phytochem Anal 18: 451-459.
Duran N, Muz M, Culha G, Duran G, Ozer B. 2011. GC-MS analysis and antileishmanial activity of two turkish propolis types. Parasitol Res 108: 95-105.

Falcão S, Vilas-Boas M, Estevinho LM, Barros C, Domingues MRM, Cardoso SM. 2010. Phenolic characterization of Northeast Portuguese Propolis: usual and unusual compounds. Anal Bioanal Chem, 396: 887-897.

Filho AAS, Resende DO, Fukui MJ, et al. 2009. In vitro antileishmanial, antiplasmodial and cytotoxic activities of phenolics and triterpenoids from Baccharis dracunculifolia D. C. (Asteraceae). Fitoterapia 80: 478-482.

Hirumi H, Hirumi K. 1989. Continuous cultivation of Trypanosoma brucei blood stream forms in a medium containing a low concentration of serum protein without feeder cell layers. $J$ Parasitol 75: 985-989.

Machado GMC, Leon LL, De Castro SL. 2007. Activity of Brazilian and Bulgarian propolis against different species of Leishmania. Mem Inst Oswaldo Cruz 102: 73-77.

Makler MT, Ries JM, William JA, et al. 1993. Parasite lactate dehydrogenase as an assay for Plasmodium falciparum drug sensitivity. Am J Trop Med Hyg 48: 739-741.

Marcucci MC. 1995. Propolis: Chemical composition, biological properties and therapeutic activity. Apidologie 26: 83-99.

Millet-Clerc J, Michael D, Simeray J, Chaumont JP. 1987. Étude preliminaire des proprietés fongistatiques de la propolis comparées à celles de quelques produits commerciaux. Plant Med Phytother 21: 3-7.

Monzote L, Cuesta-Rubio O, Campo Fernandez M, et al. 2012. In vitro antimicrobial assessment of Cuban propolis extracts. Mem Inst Oswaldo Cruz 107: 978-984. 
Moreira L, Dias L, Pereira JA, Estevinho L. 2008. Antioxidant properties, total phenols and polinic analysis of propolis from Portugal. Food Chem Toxicol 46: 3482-3485.

Moreira L, Dias T, Dias LG, Rogão M, Da Silva JP, Estevinho LM. 2011. Propolis influence on erythrocyte membrane disorder (hereditary spherocytosis): A first approach. Food Chem Toxicol, 49: 520-526.

Otoguro K, Iwatsuki M, Ishiyama A, et al. 2012. In vitro antitrypanosomal activity of some phenolic compounds from propolis and lactones from Fijian Kawa (Piper methysticum). $J$ Nat Prod 66: 558-561.

Oyaizu M. 1986. Studies on product of browning reaction prepared from glucose amine. Jpn J Nutr 44: 307-315.

Popova M, Bankova V, Butovska D, et al. 2004. Validated methods for the quantification of biologically active constituents of poplar-type propolis. Phytochem Anal 15: 235-240.

Prytzyk E, Dantas AP, Salomão K, et al. 2003. Flavonoids and trypanocidial activity of Bulgarian propolis. J Ethnopharmacol 88: 189-193.

Raz B, Iten M, Grether-Buhler Y, Kaminsky R, Brun R. 1997. The Alamar Blue asssay to determine drug sensitivity of African trypanosomes (T. b. rhodesiense, T. b. gambiense) in vitro. Acta Trop 68: 139-147.

Rice-Evans C, Miller NJ, Paganga G. 1996. Structure-antioxidant activity relationships of flavonoids and phenolic acids. Free Radic Biol Med 20: 933-956.

Robles C, Bousquet-Mélou A, Garzino S, Bonin G. 2003. Comparison of essential oil composition of two varieties of Cistus ladanifer. Biochem Systemat Ecol 31: 339-343.
Scaysbrook T, Greenaway W, Whatley FR. 1992. Relation of "antimicrobial" compounds present in poplar bud exudates to disease resistance by poplars. Z. Naturforsch 47c: 197-200.

Sforcin JM, Fernandes Jr A, Lopes CAM, Bankova V, Funari SRC. 2000. Seasonal effect on Brazilian propolis antibacterial activity. J Ethnopharmacol 73: 243-249.

Silva JC, Rodrigues S, Feás X, Estevinho LM. 2012. Antimicrobial activity, phenolic profile and role in the inflammation of propolis. Food Chem Toxicol 50: 1790-1795.

Singleton VL, Rossi JA. 1965. Colorimetry of total phenolics with phosphomolybdic-phosphotungstic acid reagents. Am J Enol Vitic 16: 144-158.

TDR. 2007. Lead discovery for drugs. Business Plan 2008-2013. $\mathrm{BL} 3$.

Trager W, Jensen JB. 1976. Human malaria parasites in continuous culture. Science 193: 673-675.

Valente MJ, Baltazar AF, Henrique R, Estevinho L, Carvalho M. 2011. Biological activities of Portuguese propolis: Protection against free radical-induced erythrocyte damage and inhibition of human renal cancer cell growth in vitro. Food Chem Toxicol 49: 86-92.

Yildirim A, Mavi A, Kara A. 2001. Determination of antioxidant and antimicrobial activities of Rumex crispus L. extracts. J Agric Food Chem 49: 4083-4089.

Zhang X, Hung TM, Phuong PT, et al. 2006. Anti-inflammatory activity of flavonoids from Populus davidiana. Arch Pharm Res 29: 1102-8. 